\title{
Physical Effects of Buckwheat Extract on Biological Membrane In Vitro and Its Protective Properties
}

\author{
Aleksandra Włoch ${ }^{1} \cdot$ Paulina Strugała $^{1}$ Hanna Pruchnik ${ }^{1} \cdot$ Romuald Żyłka $^{1}$. \\ Jan Oszmiański ${ }^{2}$ Halina Kleszczyńska ${ }^{1}$
}

Received: 3 September 2015/Accepted: 3 November 2015/Published online: 18 November 2015

(C) The Author(s) 2015. This article is published with open access at Springerlink.com

\begin{abstract}
Buckwheat is a valuable source of many biologically active compounds and nutrients. It has properties that reduce blood cholesterol levels, and so reduces the risk of atherosclerosis, seals the capillaries, and lowers blood pressure. The aim of the study was to determine quantitative and qualitative characteristics of polyphenols contained in extracts from buckwheat husks and stalks, the biological activity of the extracts, and biophysical effects of their interaction with the erythrocyte membrane, treated as a model of the cell. An analysis of the extract's composition has shown that buckwheat husk and stalk extracts are a rich source of polyphenolic compounds, the stalk extracts showing more compounds than the husk extract. The study allowed to determine the location which incorporated polyphenols occupy in the erythrocyte membrane and changes in the membrane properties caused by them. It was found that the extracts do not induce hemolysis of red blood cells, causing an increase in osmotic resistance of erythrocytes. They affect mainly the hydrophilic region by changing the degree of order of the polar heads of lipids, but do little to change the fluidity of the membrane and its hydration. The results showed also that polyphenolic
\end{abstract}

Electronic supplementary material The online version of this article (doi:10.1007/s00232-015-9857-y) contains supplementary material, which is available to authorized users.

Aleksandra Włoch

aleksandra.wloch@up.wroc.pl

1 Department of Physics and Biophysics, Wrocław University of Environmental and Life Sciences, Norwida 25, 50-375 Wrocław, Poland

2 Department of Fruit, Vegetable and Cereal Technology, Wrocław University of Environmental and Life Sciences, Chełmońskiego 37/41, 51-630 Wrocław, Poland substances included in the extracts well protect the membranes of red blood cells against oxidation and exhibit antiinflammatory effect.

Keywords Buckwheat extracts - UPLC analysis · Red blood cell membrane · FTIR spectroscopy · Dichroism · Biological activity

$\begin{array}{ll}\text { Abbreviations } \\ \text { AA } & \text { L (+) ascorbic acid } \\ \text { AAPH } & \text { 2,2'-azobis(2-amidinopropane)hydrochloride } \\ \text { BH } & \text { Buckwheat husk extract } \\ \text { BS } & \text { Buckwheat stalk extract } \\ \text { COX } & \text { Cyclo-oxygenase } \\ \text { DPH } & \text { 1,6-diphenyl-1,3,5-hexatriene } \\ \text { DPH-PA } & \text { 3-(4-(6-phenyl)-1,3,5-hexatrienyl) } \\ & \text { phenylpropionic acid } \\ \text { Laurdan } & \text { (6-dodecanoyl-2-dimethylaminonaphthalene) } \\ \text { MDA } & \text { Malondialdehyde } \\ \text { MC540 } & \text { Merocyanine 540 } \\ \text { MRBC } & \text { Red blood cell membrane } \\ \text { RBC } & \text { Red blood cell } \\ \text { TBA } & \text { 2-thiobarbituric acid } \\ \text { TCA } & \text { Tricholoroacetic acid } \\ \text { TMPD } & \text { Tetramethyl- } p \text {-phenylenediamine }\end{array}$

\section{Introduction}

The increasing demand for nutraceutic products and gluten-free cereal-based products creates the need for entry into the man's daily diet of new products. One potential pseudo-cereal with these properties is buckwheat $(\mathrm{Li}$ and 
Zhang 2001). It is a plant known and cultivated for thousands of years in North and East Asia. Currently, buckwheat is grown also in Europe. Its most popular genus is Fagopyrum esculentum Moench. This plant is rich in starch and protein (Dizlek et al. 2009). From the mentioned regions, a lot of functional foods containing buckwheat have entered the world market, such as e.g. pasta.

Scientific studies show that buckwheat has antioxidant, antiatherogenic, neuroprotective, and photoprotective effects, as well as cytotoxicity and inhibitory activity against angiotensin-I-converting enzyme and $\alpha$-amylase (Aoyagi 2006; Hinneburg et al. 2006; Kim et al. 2007; Liu et al. 2008; Pu et al. 2004; Sun and Ho 2005; Wojcicki et al. 1995). It was also shown that the compounds identified in buckwheat seeds lower cholesterol and act favorably on the digestive system (Wronkowska and SoralŚmietana 2008). It is, therefore, a plant that has a number of beneficial properties for humans, but it is not enough popular and too rarely present in the daily human diet.

The subject of our research is the extracts obtained from husks (BH) and stalks (BS) of buckwheat (Fagopyrum esculentum Moench). In the literature, there are no reports regarding the impact of these extracts on biological objects, such as cell or cell membrane. In our earlier publications (Pruchnik et al. 2015), we looked at the impact of BS and $\mathrm{BH}$ polyphenolic extracts on fluidity of a one-component model membrane, in particular on the main phase transition temperature of dimyristoylphosphatidylcholine (DMPC). In this work, we present the results of further studies on the extracts of buckwheat. We are continuing research on the impact of the above-mentioned extracts on the physical parameters of the already much more complex biological membrane model, i.e., the red blood cell membrane (MRBC). In addition, we check their biological activity based on antioxidant, anti-inflammatory, and hemolytic activity. We also present, on the basis of ultra-performance liquid chromatography (UPLC) analysis, the exact composition of the polyphenol composition of the tested extracts. Moreover, a completely new element of the proposed research is to measure the coefficient of dichroism and order parameter in the erythrocyte membrane modified with the extracts from $\mathrm{BH}$ and BS using the Fourier Transform Infrared Spectroscopy (FTIR) technique. Due to the lack of specialized, available literature referring to those measurements, our work is pioneering. For testing, we used the red blood cell (RBC), which is a very good research model, because it meets the basic functions assigned to the cell membrane (active and passive transport, creation of ion and electric gradients) and at the same time has a simplified structure compared to other cell membranes.

\section{Materials and Methods}

\section{Reagent and Standard}

Formic acid, methanol, AA $(\mathrm{L}(+)$ ascorbic acid), AAPH (2,2'-azobis(2-amidinopropane)hydrochloride), MC540 (merocyanine 540), and enzyme COX-2 (cyclo-oxygenase) were purchased from Sigma-Aldrich (Steinheim, Germany). Acetonitrile was purchased from Merck (Darmstadt, Germany). Quercetin-3-O-glucoside, quercetin 3-Ogalactoside, quercetin-3-O-rutinoside, $\quad(+)$ catechin, (-)epicatechin, procyanidin $\mathrm{B} 2-3-O$-gallate, procyanidin $\mathrm{B} 3$, vitexin, and luteolin-3-O-glucoside were purchased from Extrasynthese (Lyon, France). The DPH-PA (3-(4-(6phenyl)-1,3,5-hexatrienyl) phenylpropionic acid), Laurdan ((6-dodecanoyl-2-dimethylaminonaphthalene)), and DPH (1,6-diphenyl-1,3,5-hexatriene) fluorescence probes were purchased from Life Technologies (California, USA).

\section{Erythrocyte Cells and Erythrocyte Membranes}

The investigation was conducted with erythrocytes (RBC) and their membranes (MRBC) obtained from fresh heparinated pig blood according to the method of Dodge et al. (1963). The choice of pig erythrocytes was dictated by the fact that this cell's percentage content of lipids is closest to that of the human erythrocyte, and the blood was readily available. Erythrocytes are also a good research model due to its simplified structure compared to other cell membranes (they have only outer membrane, without internal organelles) and perform enough functions for being treated as a representative model.

Fresh blood was taken each time to a physiological solution of sodium chloride with heparin added. The content of erythrocyte membranes in the samples was determined on the basis of protein concentration, which was assayed using the Bradford method (1976), and it was $100 \mathrm{mg} / \mathrm{ml}$.

\section{Plant Material}

Buckwheat husk $(100 \mathrm{~g})$ and stalk were harvested from the Garden of Medicinal Plants herbarium of the Medical University in Wroclaw, Poland, by cultivation in the University's experimental field. After harvest, the BH and BS were directly frozen in liquid nitrogen and freeze-dried (24 h; Alpha 1-4 LSC, Christ, Germany). The homogeneous powders were obtained by crushing the dried tissues using a closed laboratory mill to avoid hydration. Powders were kept in a refrigerator $\left(-80{ }^{\circ} \mathrm{C}\right)$ until extract preparation. 


\section{Extraction Procedure and the Content of Polyphenols}

The extraction procedure of polyphenols was described previously by Gąsiorowski et al. (1997). Polyphenols were isolated from hulls and leaves by extraction with water containing $200 \mathrm{ppm} \mathrm{SO}$, the ratio of this solvent to leaves being 3:1 (v/v). The extract was adsorbed on Purolite AP 400 resin (UK) for further purification. The polyphenols were then eluted out with $80 \%$ ethanol, concentrated, and freeze-dried. The content of polyphenols in individual preparations was determined by means of UPLC/DAD and the UPLC/ESI/MS method of analyses described earlier by Oszmiański et al. (2011).

\section{Hemolytic Activity and Osmotic Resistance}

The hemolytic method was described earlier by Cyboran et al. (2015). Buckwheat extracts were added in the concentration: $0.01,0.025,0.05,0.075$, and $0.1 \mathrm{mg} \mathrm{ml}^{-1}$. The extent of hemolysis was measured at $2 \%$ hematocrit. The supernatant was assayed for hemoglobin content using an UV-Vis spectrophotometer (Specord 40, AnalytikJena) at $540 \mathrm{~nm}$ wavelength. Hemoglobin concentration in the supernatant, expressed as percentage of hemoglobin concentration in the supernatant of totally hemolyzed cells, was assumed as the measure of the extent of hemolysis.

The osmotic resistance was investigated using the spectrophotometric method described in our earlier work (Włoch et al. 2013) with minor modification. A red blood cell (at $2 \%$ hematocrit) suspension containing BH and BS extracts of $0.05 \mathrm{mg} \mathrm{ml}^{-1}$ concentration was prepared. On the basis of the results obtained, the relation was determined between the percentage of hemolysis and $\mathrm{NaCl}$ concentration in the solution. Next, using the obtained plots, the $\mathrm{NaCl}$ percent concentrations that caused $50 \%$ hemolysis $\left(C_{50}\right)$ were found. The $C_{50}$ values were taken as the measure of osmotic resistance. If a determined sodium chloride concentration is higher than that of control cells, the osmotic resistance of the erythrocytes is regarded as lower, and vice versa.

\section{Shape of Erythrocytes}

The shape of red blood cells modified with $\mathrm{BH}$ and BS extracts was investigated using the optical and scanning electron microscopes. The methods were described earlier in Włoch et al. (2013).

For investigation with the optical microscope, the red cells contained 0.01 and $0.1 \mathrm{mg} \mathrm{ml}^{-1}$, and with the scanning electron microscope the concentration of the $\mathrm{BH}$ and BS extracts was $0.05 \mathrm{mg} \mathrm{ml}^{-1}$. The individual forms of erythrocyte cells were ascribed morphological indices according to the Bessis and Brecht scale (Deuticke 2003), which for stomatocytes assume negative values from -1 to -4 and for echinocytes from 1 to 4 .

\section{Fluidity and Packing Arrangement of the Membrane}

In order to determine the likely location of the polyphenolic compounds in the membrane and examine their impact on physical parameters of erythrocyte membrane, the fluorimetric and infrared spectroscopy method was applied. The dichroism method was innovatively used for the erythrocyte membrane.

\section{Fluorimetric Methods}

The fluorescent probes Laurdan, DPH, and MC540 were used to monitor the effects at different bilayer depths, and to obtain additional information about the location of the components of $\mathrm{BS}$ and $\mathrm{BH}$ extracts in the erythrocyte membrane. Merocyanine 540 (MC 540) is a probe adsorbing at the membrane surface. Its negative charge is localized near the membrane bilayer interface, just above the glycerol skeleton (Alay et al. 2003). Packing density in the hydrophilic part of lipids of the erythrocyte membrane was studied using the Laurdan fluorescence probe, using method described earlier by Włoch et al. (2013) with minor modification. DPH probe is supposed to distribute in the hydrophobic part of the bilayer. BH and BS extracts were added at concentrations ranging from 0.01 to $0.1 \mathrm{mg} \mathrm{ml}^{-1}$. The excitation and emission wavelengths were as follows: for DPH, $\lambda_{\mathrm{exc}}=360 \mathrm{~nm}$ and $\lambda_{\mathrm{em}}=425 \mathrm{~nm}$; for Laurdan, $\lambda_{\text {exc }}=360 \mathrm{~nm}$ and the emission wavelengths were $\lambda_{\mathrm{em}}=440 \mathrm{~nm}$ and $\lambda_{\mathrm{em}}=490 \mathrm{~nm}$; and for MC540, $\lambda_{\mathrm{exc}}=540 \mathrm{~nm}$ and $\lambda_{\mathrm{em}}=590 \mathrm{~nm}$.

Packing density in the hydrophilic part of lipids of the erythrocyte membrane was determined on the basis of generalized polarization (GP) of Laurdan, calculated with the formula (Parasassi et al. 1998):

$\mathrm{GP}=\frac{I_{\mathrm{b}}-I_{\mathrm{r}}}{I_{\mathrm{b}}+I_{\mathrm{r}}}$,

where $I_{\mathrm{b}}$ is fluorescence intensity at $\lambda=440 \mathrm{~nm}$ and $I_{\mathrm{r}}$ is fluorescence intensity at $\lambda=490 \mathrm{~nm}$.

Fluorescence anisotropy $(A)$ for DPH probe was calculated using the formula (Lakowicz 2006):

$A=\frac{I_{\mathrm{II}}-G I_{\perp}}{I_{\mathrm{II}}+G I_{\perp}}$,

where $I_{\mathrm{II}}$ and $I_{\perp}$-fluorescence intensities observed in directions parallel and perpendicular to the polarization direction of the exciting wave, respectively. $G$ is an apparatus constant dependent on emission wavelength. 


\section{Fourier Transform Infrared Spectroscopy studies}

The FTIR experiments were prepared as follows: red blood cell membrane (MRBC) was washed three times in $0.9 \%$ $\mathrm{NaCl}$ solution; next, the ghost suspension was incubated $(600 \mu \mathrm{l}$ ghosts $+600 \mu \mathrm{l}$ physiological salt or physiological salt with the extracts 0.1 at mg ml${ }^{-1}$ concentration) for $24 \mathrm{~h}$ at $37^{\circ} \mathrm{C}$. After incubation, the samples were centrifuged for $15 \mathrm{~min}$ at $30,000 \times g$, and $50 \mu \mathrm{l}$ condensed membrane suspension was applied on the $\mathrm{ZnSn}$ plate. The plate coated with the ghost layer was then placed for $24 \mathrm{~h}$ in a vacuum to remove the water. To rehydrate the film, $100 \mu 1 \mathrm{D}_{2} \mathrm{O}$ or $\mathrm{H}_{2} \mathrm{O}$ was added on the sample surface and film was incubated for $24 \mathrm{~h}$ in $4{ }^{\circ} \mathrm{C}$. The measurements of the dry and rehydrated films were performed using a Thermo Nicolet 6700 MCT (Thermo Fisher Scientific, Waltham, MA), and each single spectrum was obtained from 128 records at $2 \mathrm{~cm}^{-1}$ resolution in the range $700-4000 \mathrm{~cm}^{-1}$. For each film, the measurements were made using polarized and unpolarized light. Preliminary elaboration of a spectrum was done using the EZ OMNIC v 8.0 program, also of the Thermo Nicolet make. After filtering the noise out from the spectrum of the object studied, the spectrum of the $\mathrm{D}_{2} \mathrm{O}$ or $\mathrm{H}_{2} \mathrm{O}$ was subtracted in order to remove a strong band of water and the baseline was corrected.

Fluidity and Hydration of Membrane In unpolarized spectra thus prepared, we examined four bands associated with lipids located in the range $3000-2800 \mathrm{~cm}^{-1}$ from vibrations of $\mathrm{CH}_{2}$ and $\mathrm{CH}_{3}$ groups of alkyl chains, in $1760-1700 \mathrm{~cm}^{-1}$, which correspond to carbonyl group $(\mathrm{C}=\mathrm{O})$ vibrations, $1360-1200 \mathrm{~cm}^{-1}$ corresponding phosphate group $\left(\mathrm{PO}_{2}^{-}\right)$vibrations, and about $972 \mathrm{~cm}^{-1}$-trimethyl ammonium group vibrations. We also investigated the I amide band $\left(1700-1600 \mathrm{~cm}^{-1}\right)$ that are generally employed to study protein secondary structures. Principal amide I frequencies of protein are $\beta$-sheet strong $\left(1612-1640 \mathrm{~cm}^{-1}\right), \quad$ random $\left(1645 \mathrm{~cm}^{-1}\right), \quad \alpha$-helix $\left(1650-1657 \mathrm{~cm}^{-1}\right)$, and $\beta$-sheet weak $\left(1670-1690 \mathrm{~cm}^{-1}\right)$ (Pelton and McLean 2000).

The frequency of methylene and methyl groups of alkyl chains depend on mobility (fluidity) of the chains and increase, e.g., with increasing temperature or during transition from the gel state to the liquid crystalline state. The increase in wavenumber of these bands testifies to an increase of liquidity of the hydrophobic part of the membrane.

The carbonyl group and even more the phosphate groups form hydrogen bonds with water. The carbonyl group can bind one molecule of water, while the phosphate group can bind a few. Hence the carbonyl and phosphate bands of phospholipids are the sum of the vibrations of $\mathrm{C}=\mathrm{O}$ or $\mathrm{PO}_{2}$ groups that are at different degrees of hydration (Attar et al. 2000; Lewis et al. 1994). Vibrations of $\mathrm{C}=\mathrm{O}$ and $\mathrm{PO}_{2}$ groups which do not have water bonds are represented by the wavenumbers $\approx 1742$ and $\approx 1253 \mathrm{~cm}^{-1}$, respectively. Each bound water molecule moves these values by about $20 \mathrm{~cm}^{-1}$ in the direction of smaller values. The changes observed in these bands testify, therefore, to changes in the degree of hydration of the carbonyl and phosphate groups. Similar changes are also observed when the membrane embeds the compounds having in their structure $\mathrm{OH}$ groups which may also form hydrogen bonds with the carbonyl groups or phosphoric lipids.

Infrared Linear Dichroism Spectroscopy Polarized infrared spectroscopy has proven in the past to be a powerful tool for the determination of the orientation and conformation of specific segments within macroscopically aligned bilayers (Binder 2003; Okamura et al. 1990). We used this technique to determine the effects of $\mathrm{BH}$ and $\mathrm{BS}$ extracts on the conformation of MRBC. For polarized ATR measurements, we used an ZnSn ATR 10-reflective crystal, face angle $v=45^{\circ}$. A grid polarizer on KRS5 was placed behind the ATR unit, and the settings for parallel and perpendicular polarized light were under manual control.

Infrared spectra of the solid and hydrated film were recorded with parallel and perpendicular polarized light, using parallel and perpendicular polarized spectra of the blank $\mathrm{ZnSn}$ plate as single-beam references. These spectra were used to calculate the dichroic ratio $\mathrm{R}$ of a particular absorption band. $\mathrm{R}$ is defined as the ratio of the integrated absorption intensity of the infrared radiation polarized parallel $\left(A_{\mathrm{II}}\right)$ to that polarized perpendicular $\left(A_{\perp}\right)$ to the plane of incidence. The plane of incidence is determined by the incoming and the reflected IR beam (Binder 2003; Hübner and Mantsch 1991).

$R=\frac{A_{\mathrm{II}}}{A_{\perp}}$

Based on the dichroic ratio $R$, is determined the order parameter $S_{\mathrm{IR}}$, and connected with them the mean tilt angle $\beta$ of the transition moment of the active group, with respect to the normal of the ATR crystal plane. For the polar head group (i.e., $\mathrm{C}=\mathrm{O}$ double-bond vibration, $\mathrm{PO}_{2}{ }^{-}$vibrations, $\mathrm{CO}-\mathrm{O}$ single-bond vibration, and $\mathrm{N}-\mathrm{CH}_{3}$ vibration), we used the Eq. (4):

$S_{\mathrm{IR}}=\frac{R-2}{R+1,45}$

or

$S_{\mathrm{IR}}=-2 \frac{R-2}{R+1,45}$

for the order parameter of the lipid chain $\left(\mathrm{CH}_{2}\right.$ stretching 
vibrations). The mean tilt angle $(\theta)$ is determined from the formula (6):

$\theta \approx \arccos \left(\sqrt{\frac{1}{3}(2 S+1)}\right)$.

\section{Biological Activity}

Biological activity of the studied extracts (BS, BH) was assessed on the basis of their antioxidant and anti-inflammatory activity.

\section{Antioxidant Activity}

The antioxidant activity of the extracts was determined using the spectrophotometric and fluorimetric methods described in our earlier work (Włoch et al. 2013) with minor modification. In the first method, the oxidizing agent was UVC radiation and in the second method AAPH oxidation inducer. The extent of lipid oxidation inhibition in the spectrophotometric method was expressed as a percentage calculated from the formula (7):

Inhibition $(\%)=\frac{\left(A_{0}-A\right)}{A_{0}} \times 100 \%$,

where $A_{0}$ is absorbance of control sample and $A$ is absorbance of sample with extract.

The percentage of lipid oxidation inhibition in fluorimetric method was calculated from the following formula (8):

Inhibition $(\%)=\frac{\left(F_{\mathrm{x}}-F_{\mathrm{u}}\right)}{\left(F_{\mathrm{k}}-F_{\mathrm{u}}\right)} \times 100 \%$,

where $F_{\mathrm{X}}$ is relative fluorescence of an UVC-irradiated sample, or oxidized by AAPH for $30 \mathrm{~min}$ in the presence of extracts, $F_{\mathrm{U}}$ is relative fluorescence of control sample, oxidized by AAPH or UVC radiation, measured after $30 \mathrm{~min}$, and $F_{\mathrm{K}}$ is relative fluorescence of the blank sample, not subjected to oxidation procedures, measured after $30 \mathrm{~min}$.

In both used methods, the antioxidant activity was determined as the concentration at which lipid peroxidation was inhibited by $50 \%$. Antioxidant activity of the extract was compared with activity of $\mathrm{L}(+)$ ascorbic acid (AA) the standard antioxidant.

\section{Anti-inflammatory Activity}

The anti-inflammatory activity of the substances, established on the basis of the modified method given in the work by Cyboran et al. (2015), was assayed with a spectrophotometric measurement of inhibition of activity of the cyclo-oxygenase (COX-2). Percentage of inhibition was calculated using the following formula (9):

Inhibition $(\%)=\frac{\Delta A_{\text {control }}-\Delta A_{\text {sample }}}{\Delta A_{\text {control }}} \times 100 \%$,

where $\Delta A_{\text {control }}$ and $\Delta A_{\text {sample }}$ denote the increase of absorbance after 3 min from substrate addition to the probe without and with substances tested, respectively.

\section{Statistical Analyses}

Data are shown as mean values \pm standard deviation $(n=6)$. These data were compared using Duncan's multiple range test. Data were analyzed by one-way analysis of variance (ANOVA) using Statistica 12.5 (StatSoft PL). Differences were considered statistically significant at $p<0.05$.

\section{Results}

\section{The Contents of Polyphenols}

The results of phenolic compound analysis of the $\mathrm{BH}$ and BS extracts by RP-UPLC-ESITOF-MS are shown in Table 1 (and Suppl. 1-5). Twenty-two flavonoids and two phenolic acid derivatives were characterized and quantified. These are presented in Table 1, with their retention times, $\mathrm{MS}^{-}$ion $\mathrm{m} / \mathrm{z}$, MS fragments, $\lambda_{\max }$, and contents. To identify compounds for which no commercial standards were available, we checked the generated molecular formula obtained by TOF analysis and also studied their respective fragments. The ion found at $\mathrm{m} / \mathrm{z} 341.0872$ and its fragments at $\mathrm{m} / \mathrm{z}, 251.1121$ and 179. 0339 was identified as caffeic acid hexose. Two compounds, 1 and 4, were detected as caffeic acid hexose in buckwheat extracts at a retention time of 2.23 and $3.59 \mathrm{~min}$, respectively.

Compound 2 at tr. 2.78 showed a mass spectrum typical for B-type procyanidin dimers with an $[\mathrm{M}-\mathrm{H}]^{-}$ion at $\mathrm{m} /$ z 577.1349 as the base peak. The ion at $\mathrm{m} / z 289.0709$ was derived from the cleavage of the link between the two procyanidin monomers through the fragmentation $(\mathrm{Gu}$ et al. 2003). The compound was identified as procyanidin B3 with the aid of a reference compound. Compounds 5 and 8 had similar mass spectra and $\lambda_{\max }$ and were tentatively identified as $(+)$ catechin and $(-)$ epicatechin, respectively, according to their retention time compared with respective standards. Two catechin glucosides were detected in this study (Suppl. 2). Compounds 3 and 6 with mass 451.1245 showed a fragment ion at $\mathrm{m} / \mathrm{z} 289.0705$ corresponding to the breaking of the catechin glucoside linkage. The present data are in agreement with Zheng et al. (2008). The peak number 7 in negative mode at 
Table 1 Phenolic compounds determined by UPLC-ESI-TOF-MS in an extract of buckwheat husk and stalk

\begin{tabular}{|c|c|c|c|c|c|c|}
\hline Compounds & $\begin{array}{l}\text { Content } \\
\text { husk } \\
\left(\mathrm{mg} \mathrm{g}^{-1}\right)\end{array}$ & $\begin{array}{l}\text { Content } \\
\text { stalk } \\
\left(\mathrm{mg} \mathrm{g}^{-1}\right)\end{array}$ & $\begin{array}{l}\mathrm{Rt} \\
(\min )\end{array}$ & $\begin{array}{l}{[\mathrm{M}-\mathrm{H}]} \\
(\mathrm{m} / \mathrm{z})\end{array}$ & MS-MS & $\begin{array}{l}\lambda_{\max } \\
(\mathrm{nm})\end{array}$ \\
\hline Caffeic acid hexose & 0.92 & 0.02 & 2.23 & 341.0872 & 251.1121/179.0339 & 323 \\
\hline Procyanidin B3 & 14.14 & 0.56 & 2.78 & 577.1349 & 289.0709 & 280 \\
\hline$(+)$ Catechin glucoside & 3.00 & 0.77 & 3.74 & 451.1245 & $289.0705 / 245.0814$ & 280 \\
\hline Caffeic acid hexose & 5.55 & 1.47 & 3.59 & 341.0872 & 251.1121/179.0339 & 323 \\
\hline$(+)$ Catechin & 4.01 & 0.99 & 4.93 & 289.0712 & 245.0818 & 280 \\
\hline (-)Epicatechin glucoside & 9.10 & 3.43 & 4.03 & 451.1245 & $289.0705 / 245.0814$ & 280 \\
\hline $\begin{array}{l}\text { 1-O-Caffeoyl-6-O-alpharhamnopyranosyl- } \\
\text { betaglycopyranoside }\end{array}$ & 16.02 & 1.06 & 4.16 & 487.1450 & $451.1250 / 179.0345 / 135.0450$ & 314 \\
\hline$(-)$ Epicatechin & 7.73 & 1.06 & 4.93 & 289.0712 & 245.0818 & 280 \\
\hline (Epi)afzelchine(epi)catechin isomer A & 1.16 & 1.45 & 5.18 & 561.1390 & $\begin{array}{l}543.1289 / 435.1066 / 425.0865 / \\
289.0710 / 271.0605\end{array}$ & 280 \\
\hline Procyanidin B2-3-O-gallate & 3.15 & 0.54 & 5.39 & 729.1448 & $577.1359 / 407.0765 / 289.0708$ & 280 \\
\hline Orientin & 1.83 & 0.29 & 6.40 & 447.0932 & $357.0622 / 327.0512 / 297.0396$ & 334 \\
\hline Isorientin & 13.00 & 22.44 & 6.47 & 447.0932 & $357.0622 / 327.0512 / 297.0396$ & 334 \\
\hline$(-)$ Epicatechin gallate & 3.60 & 1.35 & 6.89 & 441.0821 & $289.0709 / 169.0165$ & 280 \\
\hline Rutin & 21.63 & 10.30 & 7.07 & 609.1464 & 300.0269 & 360 \\
\hline Vitexin & 23.82 & 83.08 & 7.28 & 431.0983 & $311.0553 / 283.0594$ & 334 \\
\hline Heperin & 83.20 & 162.01 & 7.28 & 463.0877 & $300.0269 / 271.0618$ & 463 \\
\hline Rutin isomer & 51.86 & 89.14 & 7.38 & 609.1464 & 300.0269 & 360 \\
\hline Isoquercitrin & 49.04 & 93.31 & 7.54 & 463.0877 & $300.0269 / 271.0618$ & 463 \\
\hline Isovitexin & 25.47 & 54.69 & 7.54 & 431.0983 & $311.0553 / 283.0594$ & 334 \\
\hline Epiafzelchineepicatechin- $O$-methyl gallate & 9.50 & 14.80 & 7.81 & 727.1658 & $561.1357 / 289.0710 / 271.0605$ & 280 \\
\hline Luteolin glycoside & 2.53 & 1.03 & 8.37 & 447.1034 & 284.0562 & 348 \\
\hline ProcyanidinB2 dimethyl gallate & 0.37 & 0.35 & 9.26 & 757.1755 & $605.1243 / 289.0731$ & 280 \\
\hline Quercitrin & 13.81 & 1.03 & 9.74 & 447.0930 & $300.0269 / 179.0264$ & 463 \\
\hline Epiafzelchineepicatechin- $O$-di-methylgallate & 7.47 & 1.96 & 10.00 & 741.1820 & $469.1129 / 319.0818 / 271.0603$ & 280 \\
\hline Total & 371.91 & 547.13 & & & & \\
\hline
\end{tabular}

$487.1450 \mathrm{~m} / \mathrm{z}$ (Suppl. 3), with the fragment obtained for this compound at $\mathrm{m} / \mathrm{z}, 179.0345$, corresponds to caffeic acid. This compound was identified as 1-O-caffeoyl-6- $O$ alpha-rhamnopyranosyl-beta-glycopyranoside (swertiamacroside) according to Wang et al. (2009). The (epi) afzelchine(epi)catechin dimer isomers of propelargonidins were detected in the buckwheat extract according to $\mathrm{Gu}$ et al. (2003), and compound 9 was identified in negative mode at $\mathrm{m} / \mathrm{z} 561.1390$ and its fragments (epi) catechin at $\mathrm{m} /$ $z 289.0710$ and (epi)afzelchine at $\mathrm{m} / z 271.0605$.

According to the mass spectra, the galloylated flavanols were detected in the buckwheat samples: epicatechin gallate (peak 13) (441.0821/289.0709) and procyanidin B2-3O-gallate (peak 10) (729.1448/289.0708). Their presence in buckwheat was reported by Quettier-Deleu et al. (2000). Acylated propelargonidins and proanthocyanidins were found in both the buckwheat extracts (Suppl. 4). These compounds 20, 22, and 24, epiafzelchineepicatechin- $O$ methyl gallate, procyanidin B2 dimethylgallate, and
epiafzelchineepicatechin-O-di methyl gallate, were identified according to the mass spectra shown at $m / z, 727.1658$, 757.1755 , and 741.1820 , respectively.

These compounds were found in buckwheat also by Ölshläger et al. (2008). Five flavones and five flavonols were identified in the buckwheat samples (Suppl. 5). Compounds 11, 12, 15, 19, and 21 presented signals at $\mathrm{m} /$ $z$ 447.0932, 431.0984, 431.0983, and 447.1034, corresponding to orientin, isorientin, vitexin, isovitexin, and luteolin glucoside, respectively. The UV absorbance, mass spectra and fragmentation mass data were compared with the standards and data obtained by March et al. (2006). Flavonol compounds 14, 16, 17, 18, and 23 were identified on the basis of the measured $\mathrm{m} / \mathrm{z}$, fragment ions, and UV absorbance, and by spiking with the commercial standards. Two compounds 14 and 17 showing molecular ions at 609.1464 and fragment ion $300.0269 \mathrm{~m} / \mathrm{z}$ corresponding to the loss of the rutinose unit were identified as rutin and isomer of rutin (Suppl. $5 \mathrm{~m} / \mathrm{z}$ 609), respectively. 
Compounds 16 and 18 showed the same molecular ion at $463.0877 \mathrm{~m} / \mathrm{z}$ and a fragment at 300.0269 and 271.0618 . After comparison of retention time and UV spectrum with standards, they were identified as heperin and isoquercitrin, respectively. These compounds were described by $\mathrm{He}$ et al. (2008a) and Hvattum and Ekeberg (2003). Compounds 23 with molecular ion 447.0930 and the fragments at $\mathrm{m} /$ $z 300.0269$ and 179.0264 indicated the presence of quercitrin. The same fragmentation pattern was reported by Hvattum and Ekeberg (2003). Compound 21, with molecular ion 447.1034, fragmentation 284.0562, and retention time at $8.37 \mathrm{~min}$, corresponds to luteolin glycoside standard. These compounds were found in buckwheat also by Ölshläger et al. (2008). Five flavones and five flavonols were identified in the buckwheat samples (Suppl. 5).

Favan-3-ols (proanthocyanidin and catechin derivatives) and phenolic acid derivatives were the more abounded phenolic groups found in BH extract than in BS extract, and they constituted 107.35 and $40.11 \mathrm{mg} / \mathrm{g}$ of powder, respectively. However, the BS extract contained much more total of flavonols and flavones than BH extract, 517.32 and $286.19 \mathrm{mg} / \mathrm{g}$ of powder, respectively.

\section{Hemolytic Activity and Osmotic Resistance}

In the experiment, we examined whether buckwheat extracts induce hemolysis of red blood cells in the concentration: $0.01,0.025,0.05,0.075$, and $0.1 \mathrm{mg} \mathrm{ml}^{-1}$. The results showed that the percentage of hemolysis was at a similar level as for control blood cells and did not exceed $2 \%$. These studies showed that the tested extracts not only do not cause hemolysis, but also protect the red blood cells against it. These results are also consistent with the osmotic resistance tests.

The effect on osmotic resistance was examined for $\mathrm{BH}$ and BS extracts used in a concentration of $0.05 \mathrm{mg} \mathrm{ml}^{-1}$. This impact was established on the basis of the comparison of hemolytic curves for blood cells modified with the compounds with unmodified, control cells. Figure 1 shows the relationship between percentage of modified blood cell hemolysis (BS and $\mathrm{BH}$ ) and unmodified, and percent concentration of $\mathrm{NaCl}$. From the graph, it appears that the extract-modified cells from the outset markedly move the hemolytic curves in the direction of lower $\mathrm{NaCl}$ concentrations when compared with the control. Hemolytic curve shifting toward lower $\mathrm{NaCl}$ concentrations testifies to an increase in the osmotic resistance of erythrocytes. On the basis of the hemolytic curves, the concentration $C_{50}$ was determined, i.e., the concentration at which $50 \%$ of the erythrocytes had been hemolysed. The $C_{50}$ was 0.64 and 0.65 for $\mathrm{BH}$ and $\mathrm{BS}$, respectively. Comparing both the extracts, we see that their effect on hemolysis is roughly the same.

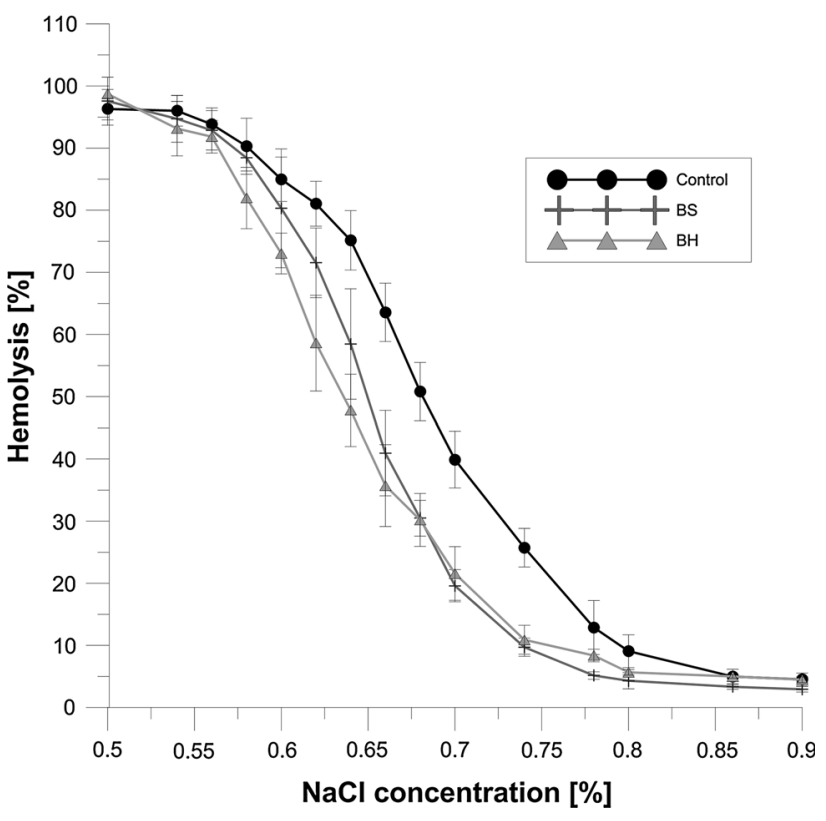

Fig. 1 Percentage of hemolysis of cells modified with BH and BS extracts at $0.05 \mathrm{mg} \mathrm{ml}^{-1}$ concentration versus sodium chloride concentration

\section{Shape of Erythrocytes}

Examination of erythrocyte shape changes induced by the extracts $\mathrm{BH}$ and BS showed that blood cells are changing shape under the influence of the extracts from the discocyte (doubly concaved) to the echinocyte (bubbles with a number of tabs) (Fig. 2). The size of these changes depends on the concentration of the extract; the higher the concentration, the more echinocytes are formed (BonarskaKujawa et al. 2014; Suwalsky et al. 2008; Suwalsky and Avello 2014;), and a larger percentage of these forms is apparent in the case of erythrocytes modified with BS extract. Table 2 shows the percentage of erythrocyte shapes when modified with BH and BS extracts at concentrations of 0.1 and $1.0 \mathrm{mg} \mathrm{ml}^{-1}$. The results indicate that $\mathrm{BH}$ and $\mathrm{BS}$ extracts are able to penetrate the erythrocyte membrane, causing a change in the erythrocyte shape.

\section{Fluidity and Packing Arrangement of the Membrane}

\section{Fluorimetric Method}

Using the fluorimetric method and 3 probes (MC540, Laurdan and DPH) that embed at different depths, changes that produce the extracts $\mathrm{BH}$ and $\mathrm{BS}$ in the MRBC were studied. For each of the extract, the experiments were conducted with five concentrations in a non-lytic range: from 0.01 to $0.1 \mathrm{mg} \mathrm{ml}^{-1}$, at $37^{\circ} \mathrm{C}$. 

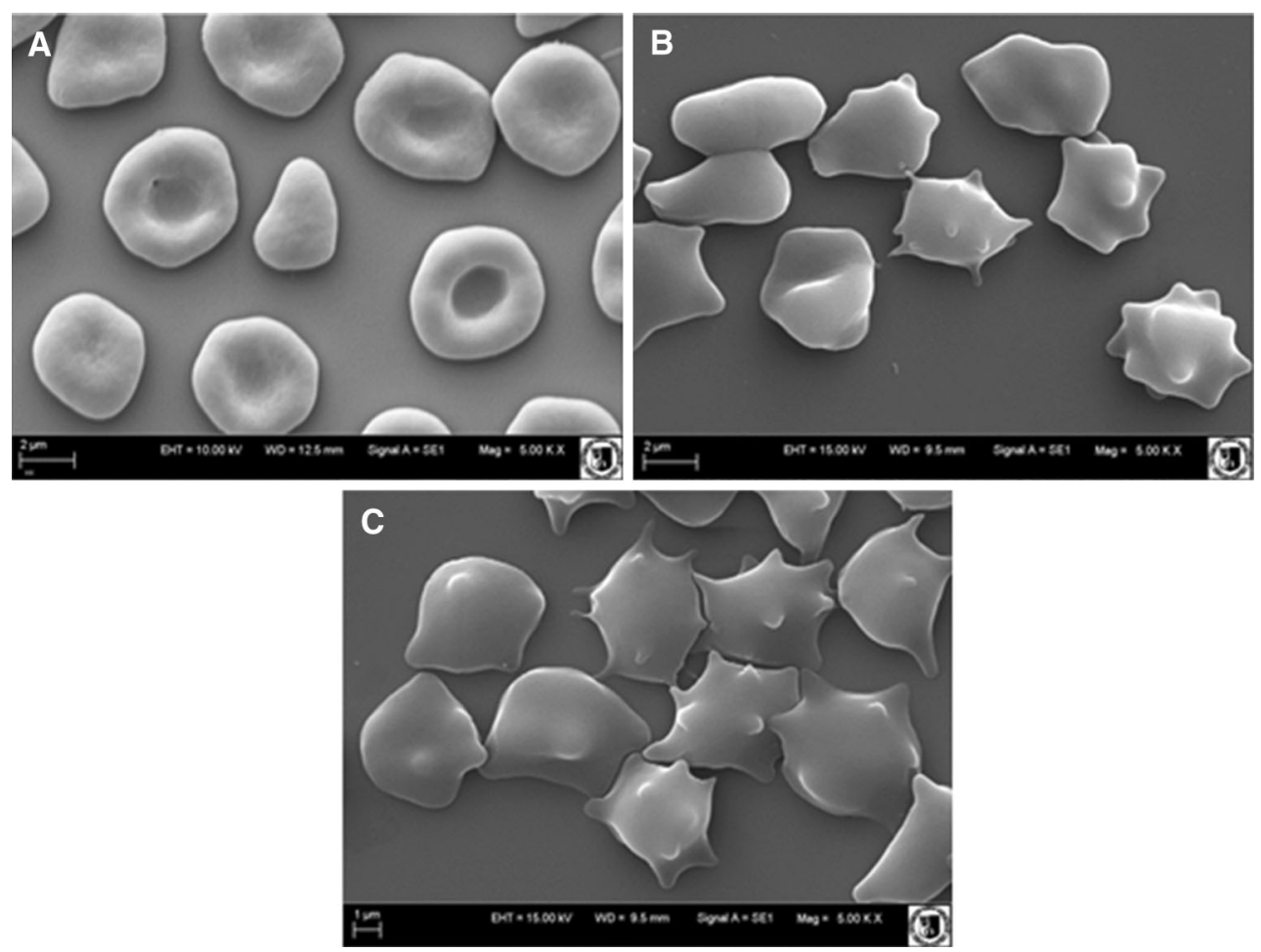

Fig. 2 Effects of BS and BH extracts on the morphology of erythrocytes observed with the electron microscope, at $0.05 \mathrm{mg} \mathrm{ml}^{-1}$ concentration. a Control (unmodified erythrocytes), b modified with BH, and $\mathbf{c}$ modified with BS

Table 2 Mean percentage of erythrocyte shapes formed in the presence of $\mathrm{BH}$ and $\mathrm{BS}$ extracts applied at 0.1 and $1.0 \mathrm{mg} \mathrm{ml}^{-1}$

\begin{tabular}{|c|c|c|c|c|c|}
\hline \multicolumn{6}{|c|}{ Average percent share of individual forms of erythrocytes \pm SD } \\
\hline \multirow[b]{2}{*}{ Shape of erythrocytes } & \multirow{2}{*}{$\begin{array}{l}\text { Control } \\
-\end{array}$} & \multicolumn{2}{|l|}{ BH extract } & \multicolumn{2}{|l|}{ BS extract } \\
\hline & & $0.1 \mathrm{mg} \mathrm{ml}^{-1}$ & $1 \mathrm{mg} \mathrm{ml}^{-1}$ & $0.1 \mathrm{mg} \mathrm{ml}^{-1}$ & $1 \mathrm{mg} \mathrm{ml}^{-1}$ \\
\hline Spherostomatocytes $(-4)$ & 0 & 0 & 0 & 0 & 0 \\
\hline Stomatocytes II $(-3)$ & 0 & 0 & 0 & 0 & 0 \\
\hline Stomatocytes I (-2) & 0 & 0 & 0 & 0 & 0 \\
\hline Discostomatocytes $(-1)$ & $4.90 \pm 0.30$ & $13.03 \pm 0.50$ & $0.40 \pm 0.21$ & 0 & 0 \\
\hline Discocytes (0) & $81.44 \pm 0.26$ & $72.93 \pm 0.31$ & $40.00 \pm 0.32$ & $11.49 \pm 0.24$ & $12.41 \pm 0.41$ \\
\hline Discoechinocytes (1) & $13.66 \pm 0.19$ & $11.78 \pm 0.34$ & $52.50 \pm 0.38$ & $24.19 \pm 0.39$ & $10.52 \pm 0.59$ \\
\hline Echinocytes (2) & 0 & $2.26 \pm 0.36$ & $6.74 \pm 0.37$ & $64.32 \pm 0.31$ & $56.21 \pm 0.44$ \\
\hline Spheroechinocytes (3) & 0 & 0 & $0.36 \pm 0.19$ & 0 & $20.86 \pm 0.50$ \\
\hline Spherocytes (4) & 0 & 0 & 0 & 0 & 0 \\
\hline
\end{tabular}

The first probe, MC540, adsorbs on the surface of the membrane, slightly above the glycerol skeleton. In aqueous environment, this probe emits little light, and in hydrophobic environment its intensity increases significantly. Studies have shown that the differences in intensity of fluorescence arise also from differences in the probe's adsorption level to the bilayer that can have varying degrees of packing order (Fig. 3). Therefore, its fluorescence should reflect the degree of order of lipids in a phospholipid bilayer. The greater the fluorescence, the lesser the packing order.
The second probe, Laurdan, locates in the hydrophilichydrophobic interface of the bilayer, and its fluorophore takes position near the phospholipid glycerol groups and is sensitive to polarity changes and dynamic properties at the membrane lipid-water interface (Parasassi et al. 1991, 1998). Studies have shown that the extracts cause a significant decrease in GP with increasing extract concentration (Table 3), BS extract showing greater changes. The decrease of the GP coefficient indicates that more water molecules are incorporated at the level of the glycerol 


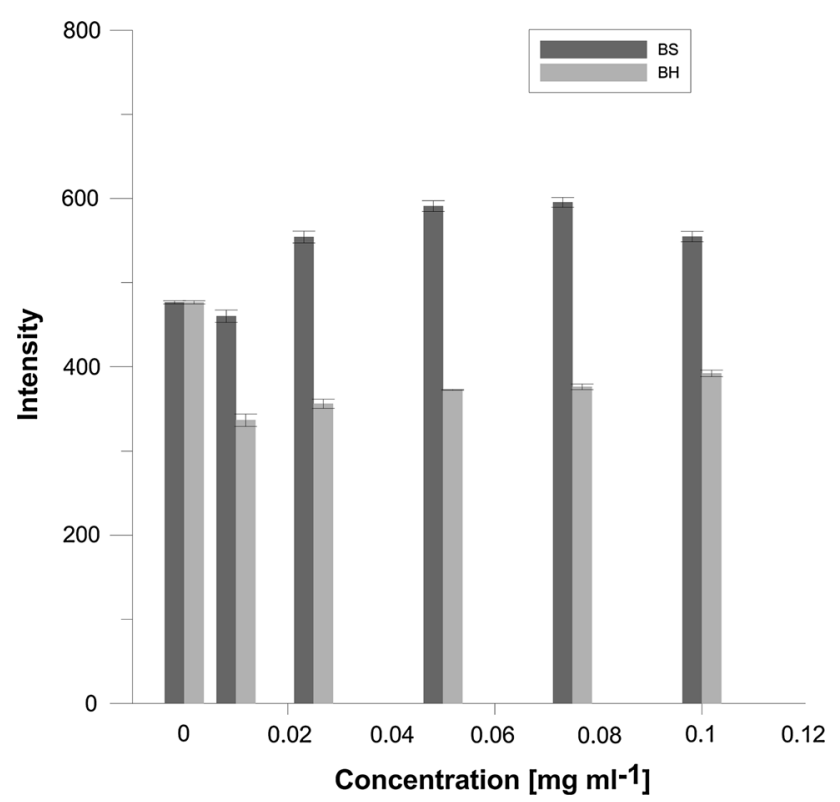

Fig. 3 Changes of intensity of MC 540 probe for erythrocytes modified with $\mathrm{BS}$ and $\mathrm{BH}$ extracts

backbone. These results suggest that the extracts cause large changes in the polar group region.

The third probe, DPH, takes position deep in the hydrophobic area. Using changes of fluorescence anisotropy of the DPH probe, the impact of BS and BH on fluidity of the erythrocyte membrane was studied. The results show a slight increase in fluorescence anisotropy with increasing concentration of extract (Table 3 ) for BH. The results obtained indicate that the extracts induce increased order in the hydrophobic area (within the hydrocarbon chains).

\section{FTIR Studies}

Fluidity and Hydration of Membrane MRBC containing many different components, aside from interacting with water molecules via hydrogen bonds, interact also with other membrane components. These interactions can be stronger than those with water molecules, so that we observe summarized bands whose frequency maxima depend on hydration of the membranes and interactions with additional compounds which can appear in the membranes.

The carbonyl band of MRBC is a sum of the components coming from various phospholipids of the membrane that form (or do not form) various hydrogen bonds. The phosphate band of the erythrocyte membrane summarizes absorption of all the different membrane phospholipids that occur in all possible hydration states. An increase in the wavenumber of the maximum of this band is indicative of the location of the lipid phosphate polar headgroup in less polar environments and a decrease in headgroup hydration (or hydrogen bonding) (Lewis et al. 1996; Lewis and McElhaney 2000; Żyłka et al. 2009). The highest frequency component refers to asymmetric stretching vibrations that are free of hydrogen bonds, while each water molecule that forms a hydrogen bond with the phosphate group diminishes the corresponding wavenumber by 20 units. The degree of hydration of individual groups can be calculated as the ratio of the surface intensity of absorbance of the groups $\left(\mathrm{CO}\right.$ or $\left.\mathrm{PO}_{2}{ }^{-}\right)$having hydrogen bonds to surface intensity of the full band.

Figure 4 shows the increase in hydration in carbonyl band for both test compounds. However, a greater hydration was observed for ghosts with BS added that was 8.2 and $3.3 \%$ for BH compared with control. In the case of the phosphate band, an increase in hydration level was observed in both cases of the tested compounds too, but a greater one for ghosts with extract added- $4.2 \%$ for $\mathrm{BH}$ and $3.6 \%$ for BS compared to control (Fig. 5).

Comparing the spectra obtained for MRBC and treated with the compounds, significant changes were observed in the carbonyl band (in particular for BS extract-Fig. 4), and much more subtle in the case of the phosphate group bands.

Infrared Linear Dichroism Spectroscopy This method makes possible a determination of the orientation and
Table 3 Values of fluorescence anisotropy (A) of DPH probe and values of generalized polarization (GP) of the Laurdan probe for MRBC modified by $\mathrm{BS}$ and $\mathrm{BH}$ at $37{ }^{\circ} \mathrm{C}$

\begin{tabular}{|c|c|c|c|c|}
\hline \multirow{2}{*}{$\begin{array}{l}\text { Extract } \\
\text { Concentration }\left(\mathrm{mg} \mathrm{ml}^{-1}\right)\end{array}$} & \multicolumn{2}{|l|}{ BS } & \multicolumn{2}{|l|}{$\mathrm{BH}$} \\
\hline & $\mathrm{GP} \pm \mathrm{SD}$ & $\mathrm{A} \pm \mathrm{SD}$ & $\mathrm{GP} \pm \mathrm{SD}$ & $\mathrm{A} \pm \mathrm{SD}$ \\
\hline Control & $0.426 \pm 0.032^{\mathrm{a}}$ & $0.260 \pm 0.003^{\mathrm{a}}$ & $0.426 \pm 0.032^{\mathrm{a}}$ & $0.260 \pm 0.003^{\mathrm{c}}$ \\
\hline 0.01 & $0.393 \pm 0.011^{\mathrm{a}}$ & $0.263 \pm 0.002^{\mathrm{a}}$ & $0.408 \pm 0.008^{\mathrm{a}}$ & $0.267 \pm 0.006^{\mathrm{c}}$ \\
\hline 0.025 & $0.358 \pm 0.026^{\mathrm{b}}$ & $0.264 \pm 0.004^{\mathrm{a}}$ & $0.366 \pm 0.028^{\mathrm{b}}$ & $0.265 \pm 0.005^{\mathrm{c}}$ \\
\hline 0.05 & $0.323 \pm 0.024^{\mathrm{b}}$ & $0.262 \pm 0.009^{\mathrm{a}}$ & $0.346 \pm 0.034^{\mathrm{b}}$ & $0.276 \pm 0.001^{\mathrm{b}}$ \\
\hline 0.075 & $0.297 \pm 0.059^{\mathrm{bc}}$ & $0.262 \pm 0.002^{\mathrm{a}}$ & $0.323 \pm 0.031^{\mathrm{bc}}$ & $0.280 \pm 0.009^{\mathrm{ab}}$ \\
\hline 0.1 & $0.225 \pm 0.054^{\mathrm{d}}$ & $0.265 \pm 0.003^{\mathrm{a}}$ & $0.254 \pm 0.034^{\mathrm{d}}$ & $0.284 \pm 0.003^{\mathrm{a}}$ \\
\hline
\end{tabular}

Statistically significant differences between results of control and modified samples are denoted Different letters $(\mathrm{a}-\mathrm{d})$ within the same column indicate significant differences at $p<0.05$ by Duncan's test 


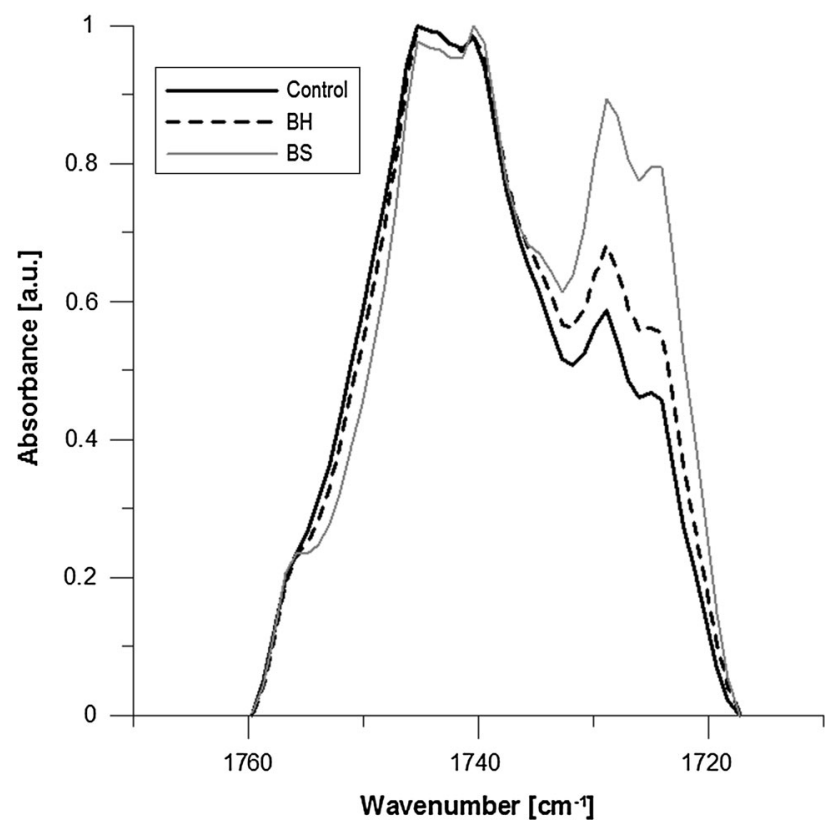

Fig. 4 Carbonyl band. The maximum at $1742 \mathrm{~cm}^{-1}$ represents vibration region of $\mathrm{C}=\mathrm{O}$ groups "free" of water molecules, while the second maximum at $1727 \mathrm{~cm}^{-1}$ comes from $\mathrm{C}=\mathrm{O}$ groups having hydrogen bonds

conformation of specific segments of lipid molecules within aligned bilayers (Fringeli 1977; Hübner and Mantsch 1991; Müller et al. 1996; Okamura et al. 1990). From the dichroic ratios $R_{\mathrm{ATR}}$ of the $\mathrm{CH}_{2}$ stretching vibrational bands, the inclination of the acyl chains of the

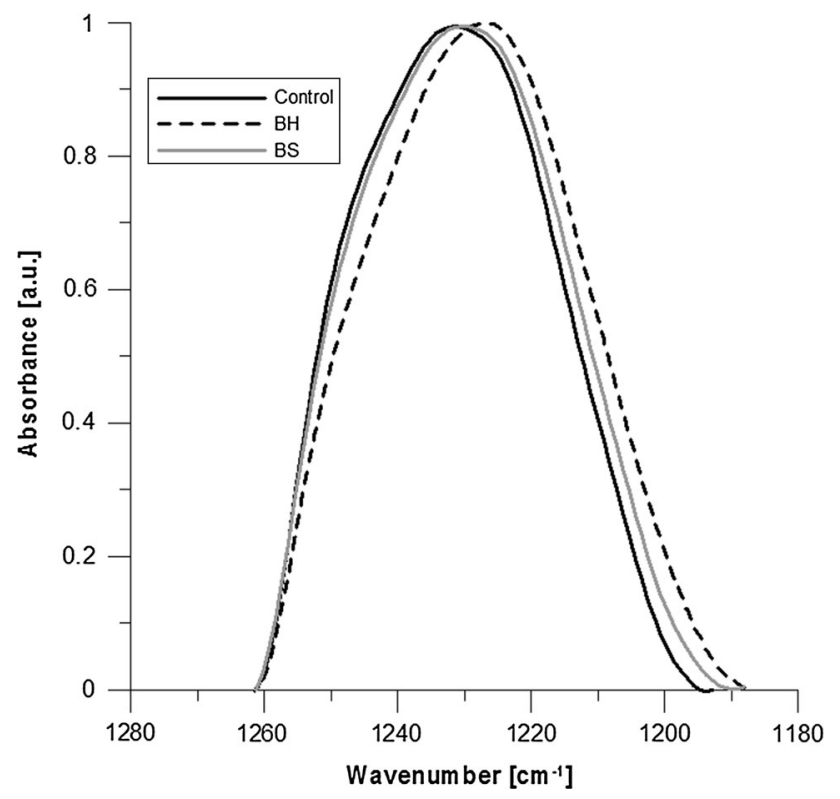

Fig. 5 Phosphate band I. A shift of phosphate band toward lower frequencies after addition of $\mathrm{BH}$ and $\mathrm{BS}$ extract is visible, which confirms binding of water molecules phospholipid can be determined. From the $R_{\mathrm{ATR}}$ values of the choline, phosphate, and carboxylate bands, it should be possible to obtain information on the state and the orientation of the head groups of the lipids. Using the formulae given in the method description, the dichroism coefficients $\left(R_{\mathrm{ATR}}\right)$ were calculated and then the order parameters $\left(S_{\mathrm{IR}}\right)$ and inclination angles $(\theta)$ of respective groups in the membrane for MRBC and MRBC modified with the extracts. The results are given in Table 4 .

On the basis of the results obtained, it can be concluded that the addition of extracts to the MRBC causes a slight increase in the order parameter $\left(S_{\mathrm{IR}}\right)$ in the acyl chains of lipids, which could mean a slight increase in order when compared to control. The angle of the axis of the chain decreases in relation to the control and chains set perpendicular to the plane. Bigger changes were observed after addition of $\mathrm{BH}$ extract.

In the case of phosphate of I and choline bands (the polar area of the lipid bilayer), the parameter $S_{I R}$ assumed negative values. This means that the head is parallel to the plane. After adding the extracts, the values grow in relation to the control, and greater growth (both bands) was observed after addition of $\mathrm{BH}$ extract. These results indicate an increase in the disorder, while the angle of the lipid head axis decreases in relation to the control.

From the amide band I, the order coefficient $\left(S_{\mathrm{IR}}\right)$ was also determined for parts corresponding to protein structures. On the basis of the results obtained, which are provided in Table 4, the impact of the extracts on the $S_{I R}$ of proteins was found. The amide band $\mathrm{I}$ is the sum of all the proteins in the membrane, which is why discussion of the results obtained is not possible.

\section{Biological Activity}

\section{Antioxidant Activity}

The antioxidant activity of the extracts was determined using spectrophotometric and fluorimetric methods. With spectrophotometric method, the antioxidant activity of $\mathrm{BH}$ and BS was evaluated based on their ability to inhibit oxidation of erythrocyte membrane lipids induced by UVC radiation. The oxidation of lipids resulted in the creation of malondialdehyde (MDA), which reacted with thiobarbituric acid (TBA) producing a colorful product. The concentration of MDA was a measure of the antioxidant activity of BS and BH. The less the created MDA (also less the colorful adduct), the higher the activity of the extract. Figure $6 a$ and $b$ shows the kinetics of oxidation of erythrocyte lipids induced by UVC in 2-h time (for three concentrations). The curves show a relation between absorbance, proportional to the degree of oxidation, and time of erythrocyte ghost UVC irradiation. From the figure, 
Table $4 R_{\mathrm{ATR}}, S_{\mathrm{IR}}$, and $\theta$ values for MRBC (control) and MRBC with extract mixtures

\begin{tabular}{|c|c|c|c|c|}
\hline & $\begin{array}{l}\text { Wavenumbers } \\
\text { (in } \mathrm{cm}^{-1} \text { ) }\end{array}$ & $R_{\mathrm{ATR}}$ & $S_{\text {IR }}$ & $\theta^{\circ}$ \\
\hline MRBC & 2919 & 1.318 & 0.353 & 41.072 \\
\hline $\mathrm{MRBC}+\mathrm{BH}$ & & 1.240 & 0.401 & 39.191 \\
\hline $\mathrm{MRBC}+\mathrm{BS}$ & $\left(\mathrm{CH}_{2}\right)$ as & 1.248 & 0.396 & 39.382 \\
\hline MRBC & 2850 & 1.143 & 0.464 & 36.702 \\
\hline $\mathrm{MRBC}+\mathrm{BH}$ & & 1.065 & 0.518 & 34.547 \\
\hline $\mathrm{MRBC}+\mathrm{BS}$ & $\left(\mathrm{CH}_{2}\right) \mathrm{s}$ & 1.088 & 0.501 & 35.215 \\
\hline MRBC & 1730 & 1.115 & -0.241 & 65.465 \\
\hline $\mathrm{MRBC}+\mathrm{BH}$ & & 0.933 & -0.306 & 68.935 \\
\hline $\mathrm{MRBC}+\mathrm{BS}$ & $\mathrm{C}=\mathrm{O}$ & 1.125 & -0.238 & 65.301 \\
\hline MRBC & 1250 & 1.200 & -0.213 & 64.077 \\
\hline $\mathrm{MRBC}+\mathrm{BH}$ & & 1.405 & -0.150 & 61.130 \\
\hline $\mathrm{MRBC}+\mathrm{BS}$ & PO2-as & 1.359 & -0.164 & 61.746 \\
\hline MRBC & 970 & 1.250 & -0.197 & 63.310 \\
\hline $\mathrm{MRBC}+\mathrm{BH}$ & & 1.750 & -0.058 & 57.129 \\
\hline $\mathrm{MRBC}+\mathrm{BS}$ & $\mathrm{N}-\mathrm{C}$ ip & 1.500 & -0.123 & 59.932 \\
\hline MRBC & $1650-1657$ & 3.841 & 0.288 & 43.546 \\
\hline $\mathrm{MRBC}+\mathrm{BH}$ & & 1.591 & -0.099 & 58.853 \\
\hline $\mathrm{MRBC}+\mathrm{BS}$ & $\alpha$-helix & 1.127 & -0.237 & 65.264 \\
\hline MRBC & 1645 & 2.267 & 0.055 & 52.521 \\
\hline $\mathrm{MRBC}+\mathrm{BH}$ & & 3.167 & 0.204 & 46.755 \\
\hline $\mathrm{MRBC}+\mathrm{BS}$ & Random & 1.614 & -0.093 & 58.590 \\
\hline MRBC & $1612-1640$ & 1.723 & -0.065 & 57.411 \\
\hline $\mathrm{MRBC}+\mathrm{BH}$ & & 1.523 & -0.117 & 59.654 \\
\hline $\mathrm{MRBC}+\mathrm{BS}$ & $\beta$-sheet & 1.839 & -0.037 & 56.241 \\
\hline MRBC & $1670-1690$ & 1.689 & -0.073 & 57.772 \\
\hline $\mathrm{MRBC}+\mathrm{BH}$ & & 1.125 & -0.238 & 65.301 \\
\hline $\mathrm{MRBC}+\mathrm{BS}$ & $\beta$-sheet & 1.963 & -0.008 & 55.073 \\
\hline
\end{tabular}

Spectra were recorded with $0^{\circ}$ or $90^{\circ}$ polarized light $\left(T=23{ }^{\circ} \mathrm{C}\right.$, thick films on a ZnSe-crystal)

it follows that with increasing irradiation time the absorption, which is a measure of lipid oxidation, increases. Based on the oxidation kinetics, for the oxidation time of $60 \mathrm{~min}$, the percentage of oxidation inhibition was calculated and from the plot of the percentage inhibition versus extract concentration, the $\mathrm{IC}_{50}$ value was found, i.e., the concentration that caused $50 \%$ decrease in erythrocyte membrane lipid oxidation. $\mathrm{IC}_{50}$ values for $\mathrm{BH}$ and $\mathrm{BS}$ and for AA are provided in Table 5.

In the fluorimetric method, erythrocyte membrane lipid oxidation was induced chemically with the AAPH compound. As a result of AAPH break-up, free radicals developed that caused damage to the probe DPH-PA observed and decline in its fluorescence intensity. Antioxidant activity of the extracts was determined on the basis of their ability to protect the probe from damage, and thus to inhibit the oxidation of lipids in the MRBC. In
Fig. $6 \mathrm{c}$ and d, the relative fluorescence of probe DPH-PA is shown. As can be seen from the figures, relative fluorescence decreases with time of oxidation and concentration, the decrease being slower as the extract concentration increases. To compare the antioxidant activity of the substances, like in the spectrophotometric method, the concentrations $\mathrm{IC}_{50}$ causing $50 \%$ inhibition of membrane lipid oxidation were determined and together with those of AA are given in Table 5 .

It has been shown that tested extracts protect the lipid MRBC when the oxidation was induced by UVC radiation as well as by the compound AAPH. In both methods, the antioxidant activity of BH and BS was close to each other with a small advantage for BH. For UV radiation, the activity of BH and BS was lower in comparison with AA, and for AAPH compound the activity of BH and BS was higher than AA (Table 5). No significant difference $(p<0.05)$ was found between antioxidant activity induced by $\mathrm{UVC}$ radiation for $\mathrm{BH}$ and $\mathrm{BH}$ extracts.

\section{Anti-inflammatory Activity}

Studies have shown that extracts of BH and BS, to varying degrees, inhibit the enzyme activity of cyclo-oxygenase 2 (COX-2). In these tests, as a measure of anti-inflammatory activity of tested substances were assumed concentration values $\left(\mathrm{IC}_{50}\right)$ responsible for $50 \%$ inhibition of COX-2 enzyme activity. The $\mathrm{IC}_{50}$ values obtained for the test substances are provided in Table 6 . The results obtained were compared with indomethacin, which is the standard medicine with anti-inflammatory effect (Cyboran et al. 2015). As indicated by the test results (Table 6), a much greater anti-inflammatory activity shows $\mathrm{BH}$ compared with the activity of BS, because at a lower concentration it causes $50 \%$ inhibition of COX-2.

\section{Discussion}

Buckwheat is known as a very good source of phenolic compounds (Fabjan et al. 2003; Kalinová et al. 2006; Kalinová and Dadáková 2006; Kalinová and Vrchotova 2009). Qualitative and quantitative analysis carried out showed the presence of polyphenolic compounds in the extracts from BS and BH (Table 1). 24 compounds have been identified in each extracts, including 22 flavonoids and 2 phenolic acids. The total content of polyphenolic compounds in $\mathrm{BH}$ extract amounted to $371.91 \mathrm{mg} \mathrm{g}^{-1}$, and in $\mathrm{BH}$ extract from approx. 1.5 times more, i.e., $547.13 \mathrm{mg} \mathrm{g}^{-1}$.

The hemolytic studies have shown that the extracts, in a wide range of concentrations, not only do not act destructively on the MRBC, without causing hemolysis of 

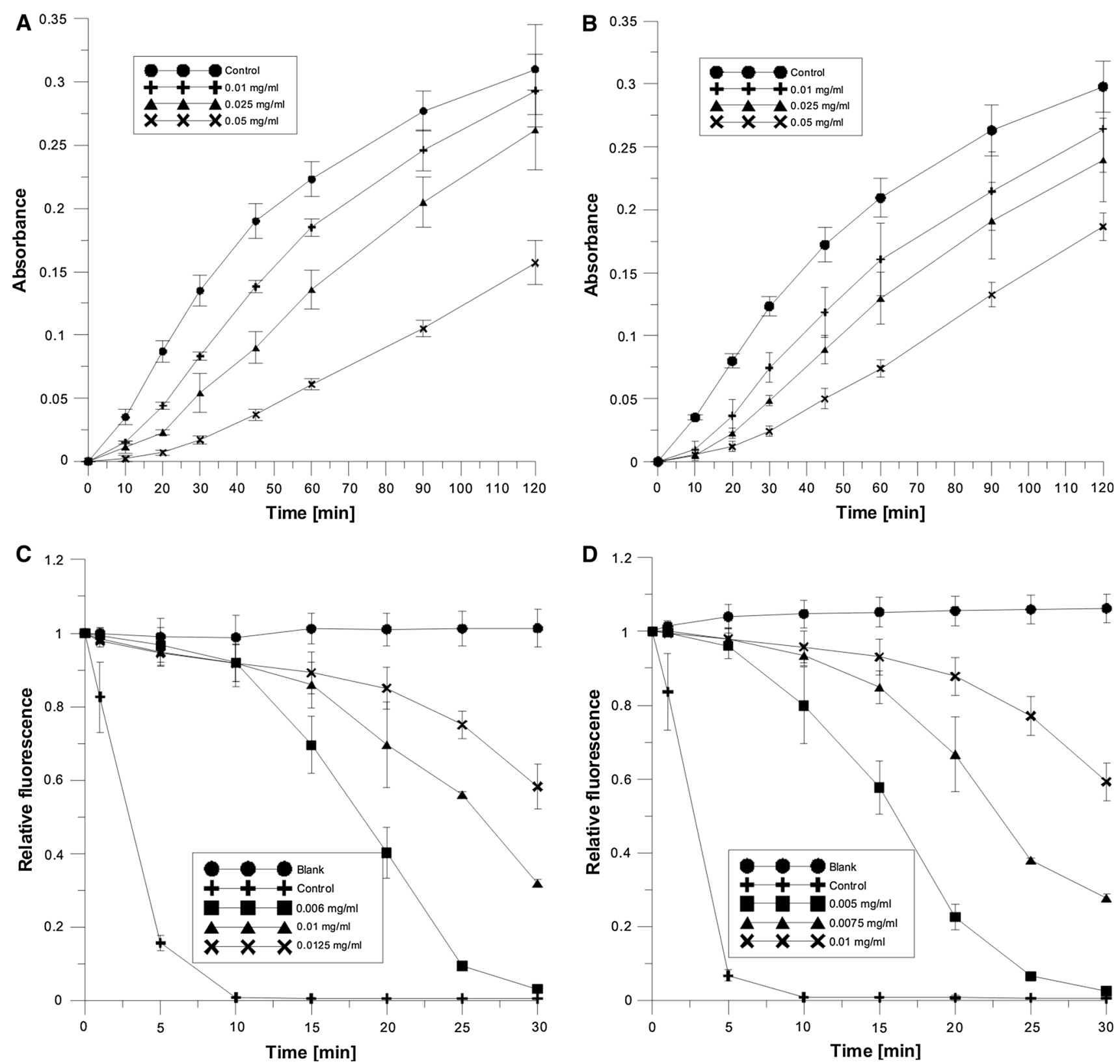

Fig. 6 Kinetics of erythrocyte membrane oxidation caused by UVC radiation: $\mathbf{a}$ in the presence of BS extract; $\mathbf{b}$ in the presence of BH extract and by the compound AAPH; $\mathbf{c}$ in the presence of BS extract; and $\mathbf{d}$ in the presence of BH extract

RBC, but strengthen it. The absence of hemolytic toxicity of different polyphenolic extracts is shown by BonarskaKujawa et al. (2014), Cyboran et al. (2012), and Suwalsky et al. (2007). These results allow believing that polyphenolic compounds present in the extracts do not penetrate deeply into the MRBC, since hemolytic action is caused by hydrophilic-hydrophobic molecules whose alkyl chains penetrate the hydrophobic region of the lipid bilayer, weakening the interaction between components of the membrane (Kleszczyńska et al. 1986; Łuczyński et al. 2013).
The results of osmotic resistance studies on erythrocytes treated with the extracts have shown that the erythrocyte membrane, possibly as a result of sealing, becomes more resistant to changes in osmotic pressure. A higher osmotic resistance of erythrocytes treated with other plant extracts is found by Cyboran et al. (2012, 2014), He et al. (2008b), and Wang et al. (2001). The increase in osmotic resistance of BS- and BH-modified RBC can be explained by the fact that polyphenolic compounds present in the extracts become incorporated mainly in the polar region of the lipid bilayer, as evidenced by the results of the fluorimetric 
Table $5 \mathrm{IC}_{50}$ values for two oxidation inducers (UVC and AAPH) in the presence of $\mathrm{BH}$ and $\mathrm{BS}$ extracts and for ascorbic acid (AA)

\begin{tabular}{lll}
\hline $\mathrm{IC}_{50}\left(\mathrm{mg} \mathrm{ml}^{-1}\right)$ & \\
\hline Compound & UVC & AAPH \\
\hline BH & $0.0300 \pm 0.0027^{\mathrm{a}}$ & $0.0100 \pm 0.0005^{\mathrm{c}}$ \\
BS & $0.0306 \pm 0.0031^{\mathrm{a}}$ & $0.0123 \pm 0.0007^{\mathrm{b}}$ \\
AA & $0.0166 \pm 0.0026^{\mathrm{b}}$ & $0.0201 \pm 0.0011^{\mathrm{da}}$ \\
\hline
\end{tabular}

Different letters $(\mathrm{a}-\mathrm{c})$ within the same column indicate significant differences at $p<0.05$ by Duncan's test

${ }^{d}$ Data presented in our earlier publication: Cyboran et al. 2015
Table 6 Values of $\mathrm{IC}_{50}$ concentrations for $\mathrm{BS}, \mathrm{BH}$, and indomethacin (IND) at which $50 \%$ inhibition of cyclooxygenase activity occurs

\begin{tabular}{ll}
\hline Compound & $\mathrm{IC}_{50}\left(\mathrm{mg} \mathrm{ml}^{-1}\right)$ \\
\hline BS & $0.3810 \pm 0.0604^{\mathrm{a}}$ \\
BH & $0.2010 \pm 0.0432^{\mathrm{b}}$ \\
IND & $0.0076 \pm 0.0007^{\mathrm{c}}$ \\
\hline
\end{tabular}

Different letters $(a-c)$ within the same column indicate significant differences as $p<0.05$ by Duncan's test research, shape, or FTIR studies presented in this paper, as well as our earlier work (Włoch et al. 2013). The presence of polyphenolic compounds in the outer part of the membrane reduces the penetration of water into the interior of the RBC driven by osmotic pressure difference.

Analysis of the shapes of red blood cells allows one to conclude that polyphenol compounds contained in buckwheat extracts incorporate mainly into the outer lipid monolayer. Echinocytes, developed as a result of extractmembrane interaction, testify to such location, according to the theory of lipid bilayer coupling (Deuticke 1968; Lim et al. 2002; Sheetz and Singer 1974). Bors et al. (2012) showed that a change in the shape and size of red blood cells depends on the total content of phenolic compounds in the extract. The results we got also showed that a greater content of polyphenolic compounds in the BS extract results in creation of more echinocytes compared with $\mathrm{BH}$ extracts (Table 2)

In experiments performed with MC540 probe, it was shown that MC540 binding is very sensitive to lipid packing of phospholipids bilayers. The research results showed that fluorescence of MC540 increases in the presence of loosely packed membrane compared to that in the presence of lipids in the gel phase (Alay et al. 2003; Manrique-Moreno et al. 2014). In our study, the enhanced fluorescence intensity of MC540 was observed for BS (Fig. 3). That increased intensity of MC540 suggests a decreased organization of lipids, which would indicate increased membrane surface area accessible for binding of the dye due to the loss of lipid packing (Langner and Hui 1999; Manrique-Moreno et al. 2014).

Fluorimetric study of erythrocyte membrane in the presence of buckwheat extracts showed a clear decline in the value of the GP, higher for the BS extract, indicating a significant increase in the disorder of membrane lipids in the hydrophilic region. Investigation of the hydrophobic area using the DPH probe showed a slight increase in fluorescence anisotropy (A) for the extract $\mathrm{BH}$ but no change for BS (Table 3). The BH extract caused a slight stiffening of the membrane in that area, which may be a consequence of modifications observed in the hydrophilic region. Higher concentrations of quercetin in $\mathrm{BH}$ extract may be responsible for the slight stiffening of the membrane. This may result from quercetin joining of the polar heads of phospholipids by hydrogen bonds and thus also affecting the alkyl chains (which may result in increased order of alkyl chains) (Pawlikowska-Pawlęga et al. 2014). Our previous studies, with respect to the unit lipid membrane model created of DMPC, showed that BH and BS extracts cause changes in both the outer area of the hydrophilic region and fluidity of the lipids in the hydrophobic region (Pruchnik et al. 2015).

In order to get confirmation of results obtained by fluorimetric method with fluorescent probes (Merocyanin, Laurdan and DPH), we conducted studies using the FTIR method.

The results obtained by FTIR confirm our observations on the location of the compounds in the membrane. An increase in hydration of the phosphate and carbonyl group suggests changes in the hydrophilic area. The results of the measurement of the coefficient of dichroism and the order parameter indicate an increase in disorder in the polar heads in the presence of the extracts, while in the chain area there is an increase in order. The angle between polar head and the normal to the membrane plane decreases in relation to the control. This means that the heads change orientation more vertically. In both cases, larger changes were observed in the presence of $\mathrm{BH}$ extract. Tested extracts may also have effect on membrane proteins, which is suggested by the changes we observed in the setting and order parameter of proteins observed by the dichroism method. On the basis of the changes observed in the degree of hydration and dichroism induced by the extracts, we can draw the conclusion that the ingredients contained in $\mathrm{BH}$ incorporate deeper into the membrane than the ones present in BS.

Biological activity of the extracts was determined on the basis of their anti-inflammatory and antioxidant activity.

Studies of antioxidant activity of the extracts showed that they protect the erythrocyte membrane against oxidation regardless of the kind of inducer (UVC radiation or AAPH compound). In both cases, the antioxidant activity 
of BH and BS was on a similar level, but the study has shown that BH and BS extract are much better antioxidants than AA in relation to the free radicals induced by AAPH compound (Table 5). Antioxidant activity of extracts from different parts of buckwheat were also studied by Gulpinar et al. (2012) and Sun and Ho (2005) using different inducers of oxidation and other research methods. There are virtually no reports concerning the antioxidant activity of extracts from $\mathrm{BH}$ and $\mathrm{BS}$ in relation to biological membranes and methods used. Only Mukoda et al. (2001) showed a good antioxidant activity of BH extract in erythrocyte membranes of the rat. Taking into account the results of the fluorimetric, FTIR, shape of erythrocytes, and antioxidant activity research, one can specify the likely molecular mechanism responsible for the antioxidant properties of the extracts. Polyphenolic compounds contained in the extracts as scavengers of free radicals reduce the amount of free radicals in the solution near the membrane, thus reducing the likelihood of their diffusion into the interior of the membrane. Therefore, we can say that the extracts constitute a kind of barrier that protects the membranes from oxidation by free radicals induced both by physical factors like UVC radiation and chemical ones like the AAPH compound.

In order to determine the anti-inflammatory activity of the extracts, we tested their effect on the inhibition of the enzyme COX-2. The studies have shown that both extracts reduce the activity of the enzyme, but a higher inhibition shows the BH extract (Table 6). This activity, however, is lower than that of indomethacin, a commonly used synthetic medicine. It can be assumed that the higher antiinflammatory activity of $\mathrm{BH}$ is due to higher content of routine and quercetin in the extract, as these compounds significantly inhibit the expression of COX-2, suggesting its high anti-inflammatory activity (Kim et al. 2013; Liu et al. 2008).

\section{Conclusions}

Extracts of husk and stalk of buckwheat are a rich source of polyphenolic compounds, the extract BS having more of these compounds. The hemolytic test results and those of osmotic resistance indicate that the extracts do not act destructively on the membrane but reinforce it, causing an increase in osmotic resistance of erythrocytes. The study of biophysical parameters of erythrocyte membrane have shown that polyphenols contained in the extracts become incorporated mainly in the hydrophilic part of erythrocyte membrane, constituting a kind of barrier for free radicals attacking the membrane from the solution. The presence of polyphenols in this part of membrane induces changes in the properties of the area, which may find reflection in small changes of fluidity of that area that we observed for BH extract. The biological activity of extracts from buckwheat specified in this study depends not only on the quantities of polyphenolic compounds but also on their kind.

The present research on the interaction of polyphenolic compounds with the erythrocyte membrane is important from the point of view of future uses of the compounds in medicine.

Acknowledgments This work was supported by funds of statutory activities of the Department of Physics and Biophysics of Wrocław University of Environmental and Life Sciences.

Open Access This article is distributed under the terms of the Creative Commons Attribution 4.0 International License (http://crea tivecommons.org/licenses/by/4.0/), which permits unrestricted use, distribution, and reproduction in any medium, provided you give appropriate credit to the original author(s) and the source, provide a link to the Creative Commons license, and indicate if changes were made.

\section{References}

Alay M, Prat J, Haro I, Rojo N, Alsina MA, Busquets MA (2003) Spectroscopic analysis of the interaction of a peptide sequence of Hepatitis G virus with bilayers. Talanta 60:269-277

Aoyagi Y (2006) An angiotensin-I converting enzyme inhibitor from buckwheat (Fagopyrum esculentum Moench) flour. Phytochemistry 67:618-621

Attar M, Kates M, Khalil MB, Carrier D, Wong PTT, Tanphaichitr N (2000) A Fourier-transform infrared study of the interaction between germ-cell specific sulfogalactosylglycerolipids and dimyristoylglycerophosphocholine. Chem Phys Lipids 106:101-114

Binder H (2003) The molecular architecture of lipid membranesnew insights from hydration-tuning infrared linear dichroism spectroscopy. Appl Spectrosc Rev 38:15-63

Bonarska-Kujawa D, Cyboran S, Żyłka R, Oszmiański J, Kleszczyńska H (2014) Biological activity of blackcurrant extracts (Ribes nigrum L.) in relation to erythrocyte membranes. Biomed Res Int 2014:1-13

Bors M, Sicińska P, Michałowicz J, Wieteska P, Gulewicz K, Bukowska B (2012) Evaluation of the effect of Uncaria tomentosa extracts on the size and shape of human erythrocytes (in vitro). Environ Toxicol Pharmacoal 33:127-134

Bradford M (1976) Rapid and sensitive method for the quantization of microgram quantities of protein utilizing the principle of proteindye binding. Anal Biochem 72:248-254

Cyboran S, Oszmiański J, Kleszczyńska H (2012) Interaction between plant polyphenols and the erythrocyte membrane. Cell Mol Biol Lett 17:77-88

Cyboran S, Oszmiański J, Kleszczyńska H (2014) Modification of the properties of biological membrane and its protection against oxidation by Actinidia argute leaf extract. Chem-Biol Interact 222:50-59

Cyboran S, Strugała P, Włoch A, Oszmiański J, Kleszczyńska H (2015) Concentrated green tea suplement: biological activity and molecular mechanisms. Life Sci 126:1-9

Deuticke B (1968) Transformation and restoration of biconcave shape of human erythrocytes induced by amphiphilic agents and changes of ionic environment. BBA 163:494-500 
Deuticke B (2003) Membrane lipids and proteins as a basis of red cell shape and its alternations. In: Bernhardt I, Ellory JC (eds) Red cell membrane transport in health and disease. Springer, Berlin, pp 27-60

Dizlek H, Özer, Inanç E, Gul H (2009) Composition of buckwheat (Fagopyrum esculentum Möench) and its possible uses in food industry. GIDA-J Food 34:317-324

Dodge JT, Mitchell C, Hanahan DJ (1963) The preparation and chemical characteristics of hemoglobin-free ghosts of erythrocytes. Arch Biochem 100:119-130

Fabjan N, Rode J, Kosir IJ, Zhuanhua W, Zheng Z, Kreft I (2003) Tartary buckwheat (Fagopyrum tataricum Gaertn.) as a source of dietary rutin and quercitrin. J Agric Food Chem 51:6452-6455

Fringeli UP (1977) The structure of lipids and proteins studied by attenuated total reflection (ATR) infrared spectroscopy. II. Oriented layers of a homologous series: phosphatidylethanolamine to phosphatidylcholine. Z Naturforsch C 32:20-45

Gąsiorowski K, Szyba K, Brokos B, Kozaczynska B, Jankowiak WM, Oszmiański J (1997) Antimutagenic activity of anthocyanins isolated from Aronia melanocarpa fruits. Cancer Lett 119:37-46

Gu L, Kelm MA, Hammerstone JF, Zhang Z, Beecher G, Holden J, Haytowitz D, Prior RL (2003) Liquid chromatographic/electrospray ionization mass spectrometric studies of proanthocyanidins in foods. J Mass Spectrom 38:1272-1280

Gulpinar AR, Orhan IE, Kan A, Senol FS, Celik SA, Kartal M (2012) Estimation of in vitro neuroprotective properties and quantification of rutin and fatty acids in buckwheat (Fagopyrum esculentum Moench) cultivated in Turkey. Food Res Int 46:536-543

He Z, Xia W, Chen J (2008a) Isolation and structure elucidation of phenolic compounds in Chinese olive (Canarium album L.) fruit. Eur Food Res Technol 226:1191-1196

He J, Lin J, Hong-Zhang J, Sun XM, Zeng CM (2008b) Dual effects of ginkgo balboa leaf extract on human red blood cells. Basic Clin Pharmacol 104:138-144

Hinneburg I, Kempe S, Rüttinger HH, Neubert RHH (2006) Antioxidant and photoprotective properties of an extract from buckwheat herb (Fagopyrum esculentum Moench). Pharmazie 61:237-240

Hübner W, Mantsch HH (1991) Orientation of specifically ${ }^{13} \mathrm{C}=\mathrm{O}$ labeled phosphatidylcholine multilayers from polarized attenuated total reflection FT-IR spectroscopy. Biophys J 59: $1261-1272$

Hvattum E, Ekeberg D (2003) Study of the collision-induced radical cleavage of flavonoid glycosides using negative electrospray ionization tandem quadrupole mass spectrometry. J Mass Spectrom 38:43-49

Kalinová J, Dadáková E (2006) Varietal and year variation of rutin content in common buckwheat (Fagopyrum esculentum Moench). Cereal Res Commun 34:1315-1321

Kalinová J, Vrchotova N (2009) Level of catechin, myricetin, quercetin and isoquercitrin in buckwheat (Fagopyrum esculentum Moench), changes of their levels during vegetation and their effect on the growth of selected weeds. J Agric Food Chem 57:2719-2725

Kalinová J, Triska J, Vrchotova N (2006) Distribution of vitamin E, squalene, epicatechin and rutin in common buckwheat plants (Fagopyrum esculentum Moench). J Agric Food Chem 54:5330-5335

Kim SH, Cui CB, Kang IJ, Sun YK, Ham SS (2007) Cytotoxic effect of buckwheat (Fagopyrum esculentum Moench) hull against cancer cells. J Med Food 10:232-238

Kim JH, Kim BB, Lee KW, Kang NJ (2013) Protective effect of rutin against ultraviolet B-induced cyclooxygenase- 2 expression in mouse epidermal cells. Food Sci Biotechnol 22:1429-1434

Kleszczyńska H, Sarapuk J, Przestalski S, Witek S (1986) The role of the alkyl chain in the interaction of glycine esters with erythrocyte and model erythrocyte lipid membranes. Stud Biophys 116:115-122

Lakowicz JR (2006) Fluorescence anisotropy. In: Lakowicz JR (ed) Principles of fluorescence spectroscopy. Plenum Press, New York, pp 353-382

Langner M, Hui SW (1999) Merocyanine 540 as a fluorescence indicator for molecular packing stress at the onset of lamellarhexagonal transition of phosphatidylethanolamine bilayers. BBA 1415:323-330

Lewis RNAH, McElhaney RN (2000) Calorimetric and spectroscopic studies of the thermotropic phase behavior of lipid bilayer model membranes composed of a homologous series linear saturated phosphatidylserines. Biophys J 79:2043-2055

Lewis RNAH, McElhaney RN, Pohle W, Mantsch HH (1994) Components of the carbonyl stretching band in the infrared spectra of hydrated 1,2-diacylglycerolipids bilayers: a reevaluation. Biophys J 67:2367-2375

Lewis RNAH, Pohle W, McElhaney RN (1996) The structure of phospholipid bilayers: differential scanning calorimetry and Fourier transform infrared spectroscopic studies of 1,2-dipoalmitoyl-sn-glycero-3-phosphorylcholine and its dialkyl and acylalkyl analogs. Biophys J 70:2736-2746

Li SQ, Zhang QH (2001) Advances in the development of functional foods from buckwheat. Crit Rev Food Sci 41:451-464

Lim G, Wortis M, Mukhopadhyay R (2002) Stomatocyte-discocyteechinocyte sequence of the human red blood cell: evidence for the bilayer-couple hypothesis from membrane mechanics. Proc Natl Acad Sci USA 99:16766-16769

Liu CL, Chen YS, Yang JH, Chiang BH (2008) Antioxidant activity of tartary (Fagopyrum tataricum (L.) Gaertn.) and common (Fagopyrum esculentum Moench) buckwheat sprouts. J Agric Food Chem 56:173-178

Łuczyński J, Frąckowiak R, Włoch A, Kleszczyńska H, Witek S (2013) Gemini ester quat surfactants and their biological activity. Cell Mol Biol Lett 18:89-101

Manrique-Moreno M, Londoño-Londoño J, Jemioła-Rzemińska M, Strzałka K, Villena F, Avello M, Suwalsky M (2014) Structural effects of the Solanum steroids solasodine, diosgenin and solanine on human erythrocytes and molecular models of eukaryotic membranes. BBA 1838:266-277

March RE, Lewars EG, Stadey CJ, Miao XS, Zhao X, Metcalfe CD (2006) A comparison of flavonoid glycosides by electrospray tandem mass spectrometry. Int J Mass Spectrom 248:61-85

Mukoda T, Sun B, Ishiguro A (2001) Antioxidant activities of buckwheat hull extract toward various oxidative stress in vitro and in vivo. Biol Pharm Bull 24:209-213

Müller E, Giehl A, Schwarzmann G, Sandhoff K, Blume A (1996) Oriented 1,2-dimyristoyl-sn-glycero-3-phosphorylcholine/ganglioside membranes: a Fourier transform infrared attenuated total reflection spectroscopic study. Band assignments; orientational, hydrational, and phase behavior; and effects of $\mathrm{Ca}^{2+}$ binding. Biophys J 71:1400-1421

Okamura E, Umemura J, Takenaka T (1990) Orientation studies of hydrated dipalmitoylphosphatidylcholine multibilayers by polarized FTIR-ATR spectroscopy. BBA 1025:94-98

Ölshläger C, Regos I, Zeller FJ, Treutter D (2008) Identification of galloylated propelargonidins and procyanidins in buckwheat grain and quantification of rutin and flavanols from homostylous hybrids originating from $F$. esculentum and $F$. homotropicum. Phytochemistry 69:1389-1397

Oszmiańki J, Wojdyło A, Gorzelany J, Kapusta I (2011) Identification and characterization of low molecular weight polyphenols in berry leaf extracts by HPLC-DAD and LC-ESI/MS. J Agric Food Chem 59:12830-12835

Parasassi T, De Stasio G, Ravagnan G, Rusch RM, Gratton E (1991) Quantitation of lipid phases in phospholipid vesicles by the 
generalized polarization of laurdan fluorescence. Biophys $\mathrm{J}$ 60:179-189

Parasassi T, Krasnowska EK, Bagatolli L, Gratton E (1998) Laurdan and prodan as polarity-sensitive fluorescent membrane probes. J Fluorescence 8:365-373

Pawlikowska-Pawlęga B, Dziubińska H, Król E, Trębacz K, JaroszWilkołazka A, Paduch R, Gawron A, Gruszecki WI (2014) Characteristics of quercetin interactions with liposomal and vacuolar membranes. BBA 1838:254-265

Pelton JT, McLean LR (2000) Spectroscopic methods for analysis of protein secondary structure. Anal Biochem 277:167-176

Pruchnik H, Włoch A, Żyłka R, Oszmiański J, Kleszczyńska H (2015) Interaction of skullcap (Scutellaria baicalensis Georgi) and buckwheat (Fagopyrum esculentum Moench) extracts with lipids bilayers. J Them Anal Calorim 121:475-484

Pu F, Mishima K, Egashira N, Iwasaki K, Kaneko T, Uchida T, Irie K, Ishibashi D, Fujii H, Kosuna K, Fujiwara M (2004) Protective effect of buckwheat polyphenols against long-lasting impairment of spatial memory associated with hippocampal neuronal damage in rats subjected to repeated cerebral ischemia. J Pharmacol Sci 94:393-402

Quettier-Deleu C, Gressier B, Vasseur J, Dine T, Brunet C, Luyckx M, Cazin M, Cazin JC, Bailleul F, Trotin F (2000) Phenolic compounds and antioxidant activities of buckwheat (Fagopyrum esculentum Moench) hulls and flour. J Ethnopharmacol 72:35-42

Sheetz MP, Singer SJ (1974) Biological membranes as bilayer couples. A molecular mechanism of drug-erythrocyte interactions. Proc Nat Acad Sci USA 71:4457-4461

Sun T, Ho CT (2005) Antioxidant activities of buckwheat extracts. Food Chem 90:743-749

Suwalsky M, Avello M (2014) Antioxidant capacity of Ugni molinae fruit extract on human erythrocytes: an in vitro study. J Membr Biol 247:703-712
Suwalsky M, Orellana P, Avello M, Villena F (2007) Protective effect of Ugni molinae Turcz against oxidative damage of human erythrocytes. Food Chem Toxicol 45:130-135

Suwalsky M, Vargas P, Avello M, Fernando V, Sotomayor CP (2008) Human erythrocytes are affected in vitro by flavonoids of Aristotelia chilensis (Maqui) leaves. Int J Pharm 363:85-90

Wang X, Wei L, Ouyang JP, Muller S, Gentils M, Cauchois G, Stoltz JF (2001) Effects of an angelica extract on human erythrocyte aggregation, deformation and osmotic fragility. Clin Hemorheol Microcirc 24:201-205

Wang Y, Guo Z, Jin Y, Zhang X, Li W, Liang X (2009) Selective enrichment with "click oligo (ethylene glycol)" column and TOF-MS characterization of simple phenylpropanoids in the fruits of Forsythia suspensa. J Sep Sci 32:2958-2966

Włoch A, Kapusta I, Bielecki K, Oszmiański J, Kleszczyńska H (2013) Activity of hawthorn leaf and bark extracts in relation to biological membrane. J Membr Biol 246:545-556

Wojcicki J, Barcew-Wiszniewska B, Samochowiec L, Rozewicka L (1995) Extractum Fagopyri reduces atherosclerosis in high-fat diet fed rabbits. Pharmazie 50:560-562

Wronkowska M, Soral-Śmietana M (2008) Buckwheat flour-a valuable component of gluten-free formulations. Pol J Food Nutr Sci 58:59-63

Zheng X, Shi P, Cheng Y, Qu H (2008) Rapid analysis of a Chinese herbal prescription by liquid chromatography-time-of-flight tandem mass spectrometry. J Chromatogr A 1206:140-146

Żyłka R, Kleszczyńska H, Kupiec J, Bonarska-Kujawa D, Hladyszowski J, Przestalski S (2009) Modifications of erythrocyte membrane hydration induced by organic tin compounds. Cell Biol Int 33:801-806 